\title{
RF POWER GENERATION ANQ COUPLING MEASUREMENTS FO' THE DIELECTRIC WAKEFIELD STEP-UP TRANSFORMER
}

\author{
M.E. Conde, W. Gai, R. Konecny, J. Power, P. Schoessow, P. Zou \\ Argonne National Laboratory, High Energy Physics Division \\ 9700 S Cass Ave, Argonne IL 60439
}

\begin{abstract}
The dielectric wakefield transformer (DWT) is one route to practical high energy wakefield-based accelerators. Progress has been made in a number of areas relevant to the demonstration of this device. In this article we describe recent bench measurements and beam experiments using 7.8 and $15.6 \mathrm{GHz}$ structures and discuss some remaining technical challenges in the development of the DWT.
\end{abstract}

\section{INTRODUCTION}

Dielectric loaded structures driven by the wakefields of a high current electron beam have been under study for some time as high frequency high gradient accelerators [1]. The simplicity of this method, as well as the relative ease with which parasitic higher order modes can be damped [2] compared to conventional structures operating at a comparable frequency makes this technology an attractive option for future high energy $e^{+} e^{-}$linear colliders.

A simple collinear drive-witness beam geometry suffers from inefficiencies due to the single bunch beam breakup instability of the drive beam unless unrealistic injection tolerances are imposed. Collinear devices are also limited to transformer ratios $<2$, and beam staging is difficult. To circumvent these problems, a transformer geometry is used [3], where the drive and witness beams pass through separate structures (figure 1). The rf pulse generated by the drive beam is transferred via waveguide to a second structure which is adjusted to have the same fundamental frequency but smaller group velocity and transverse dimensions, thus providing an accelerating field step up by compressing the rf pulse. A drive structure can be designed with sufficiently low transverse impedance [4] to avoid beam breakup problems. Multiple drive bunches are used, spaced by an integral multiple of the rf period, to provide a long accelerating pulse.

Initially it was useful to operate with a collinear drive and witness beam geometry in order to probe directly the fields generated in the drive structure. Measurement

Submitted to the proceedings of the $8 \mathrm{th}$ Workshop on Advanced Accelerator Concepts (AAC'98), Baltimore, MD, July 5-11, 1998. 


\section{DISCLAIMER}

This report was prepared as an account of work sponsored by an agency of the United States Government. Neither the United States Government nor any agency thereof, nor any of their employees, make any warranty, express or implied, or assumes any legal liability or responsibility for the accuracy, completeness, or usefulness of any information, apparatus, product, or process disclosed, or represents that its use would not infringe privately owned rights. Reference herein to any specific commercial product, process, or service by trade name, trademark, manufacturer, or otherwise does not necessarily constitute or imply its endorsement, recommendation, or favoring by the United States Government or any agency thereof. The views and opinions of authors expressed herein do not necessarily state or reflect those of the United States Government or any agency thereof. 


\section{DISCLAIMER}

Portions of this document may be illegible in electronic image products. Images are produced from the best available original document. 
structures. With optimized coupling, the $7.8 \mathrm{GHz}$ structure has a transformer ratio of 2.5 , while that of the $15.6 \mathrm{GHz}$ device is 3.6 .

\section{BENCH MEASUREMENTS AND RF COUPLING OPTIMIZATION}

In the original concept for the DWT [3], the coupling between structures was accomplished by smoothly deforming the dielectric tubes and coupling the if through a short unloaded section of waveguide which acted as a quarter wave transformer. This scheme involves no mode conversions and was found to be very efficient based on $2 \mathrm{D}$ numerical simulations [8]. The difficulty of deforming the ceramic tubes used as dielectrics led to an alternative method of rf coupling, using a section of rectangular waveguide as shown in figure 1.

The coupling of if from the drive tube into the accelerating tube involves obtaining efficient broadband $(\Delta f / f \simeq 5-10 \%)$ power transfer with two mode conversions, from cylindrical $\mathrm{TM}_{01}$ to rectangular $\mathrm{TE}_{10}$ and back again. The problem of coupling optimization in the DWT was found to involve considerably more effort than a few hours work by a "halfway decent electrical engineer" as anticipated [5]. A lengthy trial and error procedure of coupling slot adjustments and network analyzer measurements was necessary to obtain reasonable coupling between the structures.

Figure 2 shows the bench measurement setup. A tapered launcher in combination with a tapered dielectric is used to achieve good coaxial to cylindrical waveguide coupling. A waveguide to coax adapter is located at the end of the rectangular waveguide. $S_{21}$ is measured from the tapered launcher to the coaxial coupler output.

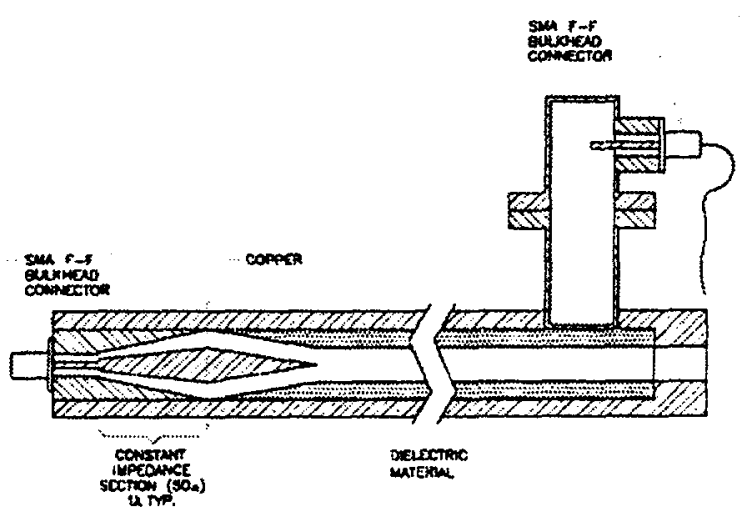

FIGURE 2. Bench measurement setup for dielectric structure to waveguide coupling measurements.

The coupling slot is located about $\lambda_{\text {wake }} / 4$ from the end of the dielectric waveguide and is longer in the azimuthal direction than in the axial. The slot allows the 


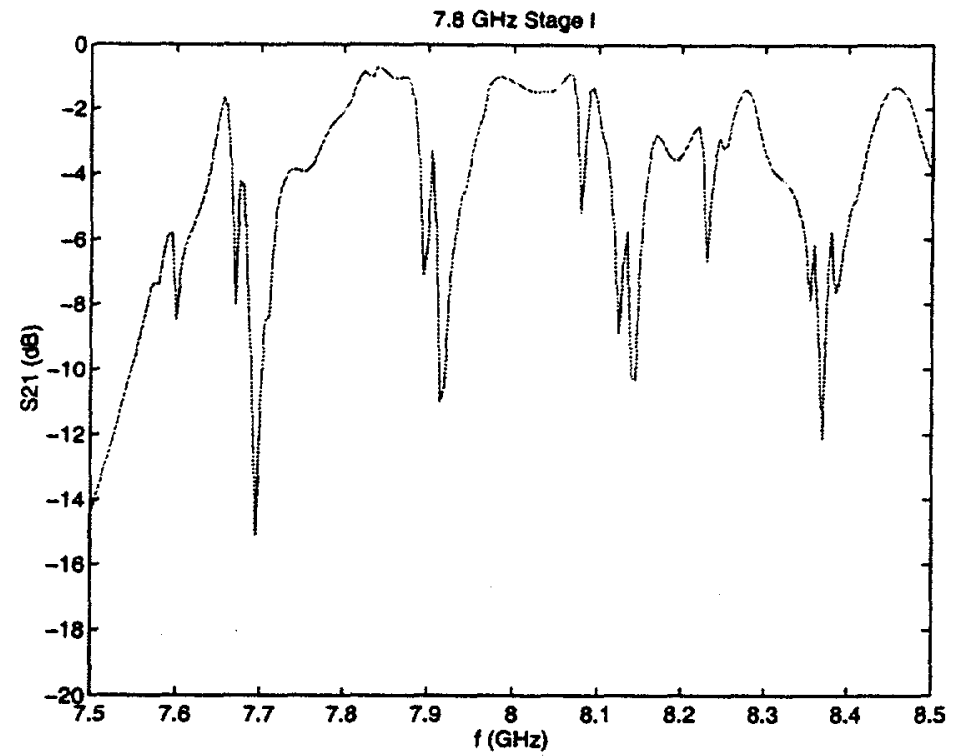

FIGURE 3. Measured $S_{21}$ for stage I of the $7.8 \mathrm{GHz}$ DWT structure.

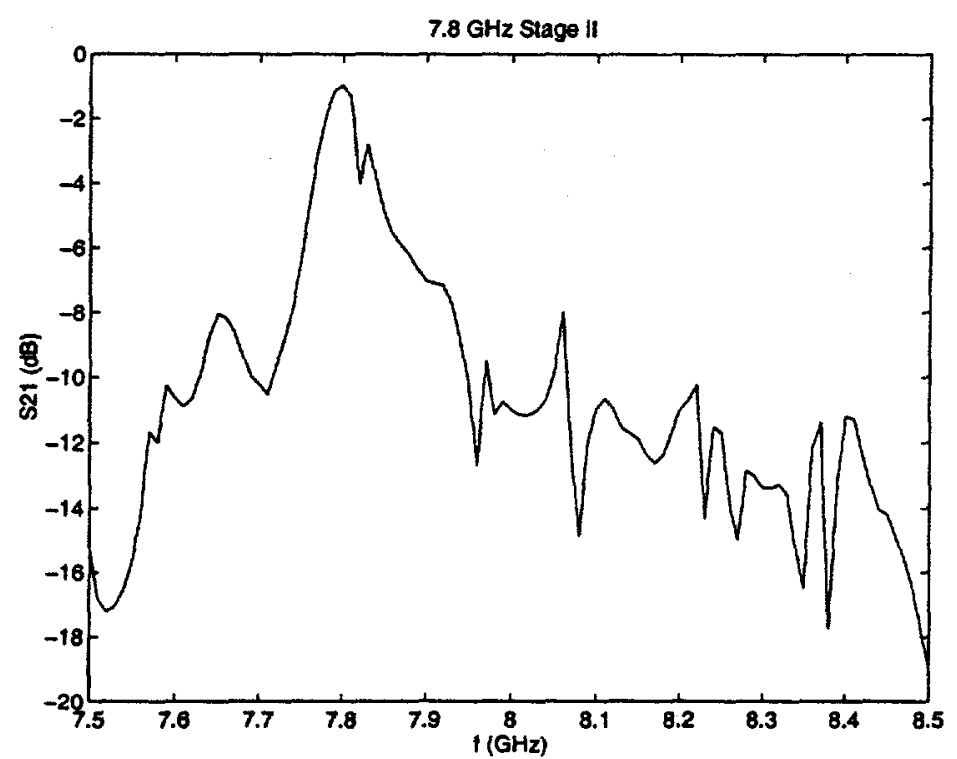

FIGURE 4. $S_{21}$ for stage II of the $7.8 \mathrm{GHz}$ DWT structure. 


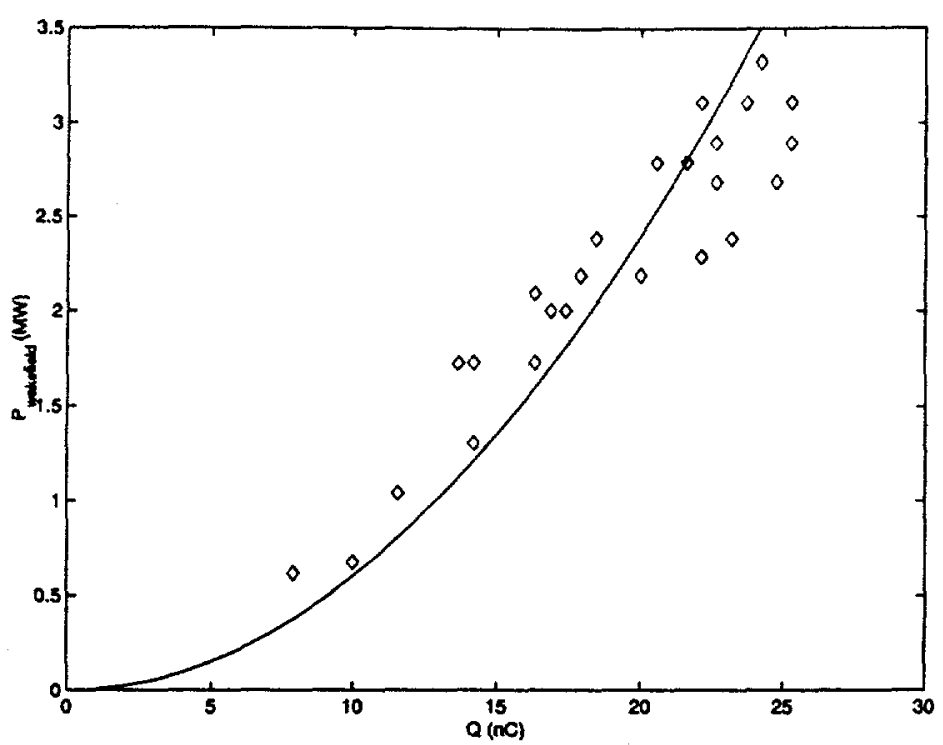

FIGURE 6. Rf power vs drive bunch charge, $7.8 \mathrm{GHz}$ dielectric structure. The scatter in the data is due to bunch length fluctuations.

\section{SUMMARY}

Considerable progress has been made towards a demonstration of the dielectric wakefield transformer. Some of the major steps on the way- optimizing the rf coupling from dielectric to transfer structure, multiple drive bunch generation in the AWA linac, and direct measurement of the rf generated by the beam- have been successfully achieved. We have some confidence that the remaining tasks can be accomplished without any major difficulties.

\section{ACKNOWLEDGEMENT}

This work was supported by the US Department of Energy, Division of High Energy. Physics, under contract W-31-109-ENG-38. 


\section{REFERENCES}

1. W. Gai, P. Schoessow, B. Cole, R. Konecny, J. Norem, J. Rosenzweig, J. Simpson, Phys. Rev. Lett. 612756 (1988)

2. E. Chojnacki, W. Gai, C. Ho, R. Konecny, S. Mtingwa, J. Norem, M. Rosing, P. Schoessow, J. Appl. Phys. 696257 (1991)

3. E. Chojnacki, W. Gai, J. Simpson, P. Schoessow, Proc. 1991 Particle Accelerator Conf. p. 2557-2559

4. W. Gai, A. D. Kanareykin, A. L. Kustov, J. Simpson, Phys. Rev. E 553481 (1997)

5. J. Simpson, private communication

6. P. Schoessow, M. E. Conde, W. Gai, R. Konecny, J. Power, J. Simpson, to appear in J. Appl. Phys.

7. M. Conde et al., submitted to Phys. Rev. Special Topics-Accelerators and Beams

8. P. Schoessow, WF-169 (unpublished)

9. "Microwave Magnetic and Dielectric Materials Catalog", Trans-Tech Corp. n.d.

10. W. Gai, X. Li, M. E. Conde, J. Power, P. Schoessow, to appear in Nucl. Inst. Meth. 